\title{
Differential Responses of the Endothelial and Epithelial Barriers of the Lung in Sheep to Escherichia coli Endotoxin
}

\author{
J. P. Wiener-Kronish, K. H. Albertine, and M. A. Matthay \\ With the technical assistance of Oscar Osorio and Maritza Neuberger \\ Cardiovascular Research Institute and Departments of Anesthesia and Medicine, University of California, San Francisco, California \\ 94143-0130; and Departments of Medicine and Physiology, Jefferson Medical College, Philadelphia, Pennsylvania 19107
}

\begin{abstract}
Although intravenous Escherichia coli endotoxin has been used extensively in experimental studies to increase lung endothelial permeability, the effect of $E$. coli endotoxin on lung epithelial permeability has not been well studied. To examine this issue in sheep, bidirectional movement of protein across the lung epithelial barrier was studied by labeling the vascular space with ${ }^{131}$ I-albumin and by instilling $3 \mathrm{ml} / \mathrm{kg}$ of an isosmolar protein solution with ${ }^{125}$ I-albumin into the alveoli. $E$. coli endotoxin was administered according to one of three protocols: intravenous alone (5-500 $\mu \mathrm{g} / \mathrm{kg})$, intravenous $(5 \mu \mathrm{g} / \mathrm{kg})$ plus low-dose alveolar endotoxin $(10 \mu \mathrm{g} / \mathrm{kg})$, and high-dose alveolar endotoxin alone (50-100 $\mu \mathrm{g} / \mathrm{kg})$. Alveolar liquid clearance was estimated based on the concentration of the instilled native protein. Sheep were studied for either 4 or $24 \mathrm{~h}$. Although intravenous $\boldsymbol{E}$. coli endotoxin produced a marked increase in transvascular protein flux and interstitial pulmonary edema, there was no effect on the clearance of either the vascular ( ${ }^{131}$ I-albumin) or the alveolar ( ${ }^{125} \mathrm{I}$-albumin) protein tracer across the epithelial barrier. High-dose alveolar $E$. coli endotoxin caused a 10 -fold increase in the number of leukocytes, particularly neutrophils, that accumulated in the air spaces. In spite of the marked chemotactic effect of alveolar endotoxin, there was no change in the permeability of the epithelial barrier to the vascular or alveolar protein tracers. Also, alveolar epithelial liquid clearance was normal. Morphologic studies confirmed that the alveolar epithelial barrier was not injured by either intravenous or alveolar $E$. coli endotoxin. Thus, the alveolar epithelium in sheep is significantly more resistant than the lung endothelium to the injurious effects of $E$. coli endotoxin. (J. Clin. Invest. 1991. 88:864-875.) Key words: $E$. coli endotoxin $\bullet$ alveolar epithelium • lung endothelium • alveolar liquid clearance $\bullet$ acute lung injury
\end{abstract}

\section{Introduction}

Intravenous endotoxin has been used in many studies to provide an experimental model of acute lung injury. In several small animal studies, $E$. coli endotoxin has been shown to initiate an inflammatory cascade, both by a direct effect on neutrophils as well as on microvascular endothelium, with accumula-

Address correspondence to J. P. Wiener-Kronish, M.D., Cardiovascular Research Institute, Box 0130, University of California, San Francisco, CA 94143-0130. 1991

Received for publication 3 August 1990 and in revised form 11 April

J. Clin. Invest.

(c) The American Society for Clinical Investigation, Inc.

0021-9738/91/09/0864/12 \$2.00

Volume 88, September 1991, 864-875 tion of inflammatory cells in the microcirculation, interstitium, and the air spaces of the lung (1-3). Also, intravenous $E$. coli endotoxin in anesthetized and awake sheep produces pulmonary hypertension, bronchoconstriction, hypoxemia, increased protein-rich lymph flow, and neutrophil sequestration in the lung (4). Although the effects of intravenous $E$. coli endotoxin on lung endothelial permeability and morphology have been well studied $(5,6)$, the effect of $E$. coli endotoxin on alveolar epithelial permeability and function has not been well investigated. Yet, the integrity of the alveolar epithelium may be critical in determining the extent of alveolar flooding and gas exchange abnormalities.

Therefore, the overall purpose of our studies was to examine the effects of intravenous and alveolar $E$. coli endotoxin on lung epithelial permeability to protein as well as the capacity of the alveolar epithelium to remove excess liquid and solutes from the air spaces of the lung. We hypothesized that alveolar edema would occur with intravenous $E$. coli endotoxin only if a substantial quantity of interstitial edema developed and overflowed into the air spaces, or if the alveolar epithelial barrier were injured. Therefore, we first evaluated the effect of intravenous $E$. coli endotoxin $(5-50 \mu \mathrm{g} / \mathrm{kg})$ and intravascular volume expansion with a crystalloid solution on lung lymph flow and extravascular lung water accumulation. There was a marked increased in protein-rich lung lymph flow, but only interstitial edema developed.

Therefore, to more precisely assess the effect of $E$. coli endotoxin on the alveolar epithelium, we measured two well-described properties of the epithelial barrier in vivo: the relative impermeability of the barrier to protein flux and the capacity of the epithelium to actively transport solutes (liquid) from the air spaces of the lung $(7,8)$. Studies were carried out over both 4 and $24 \mathrm{~h}$ with one of the following protocols. First, $E$. coli endotoxin was administered intravenously to increase lung endothelial permeability. Second, the combination of intravenous and low dose alveolar $E$. coli endotoxin was studied. Third, the effect of high doses of intraalveolar $E$. coli endotoxin over 4 and $24 \mathrm{~h}$ was examined to determine whether there was a dose-dependent or a time-dependent epithelial or endothelial injury secondary to the instillation of $E$. coli endotoxin adjacent to the alveolar epithelium. Positive control studies using oleic acid over $4 \mathrm{~h}$ and live Pseudomonas aeruginosa bacteria over $24 \mathrm{~h}$ have been included to provide a quantitative comparison with the effects of $E$. coli endotoxin on the epithelial barrier.

\section{Methods}

\section{Surgical preparation and ventilation}

A total of 47 female and wethered yearling sheep ( $36 \pm 6 \mathrm{~kg}$; mean \pm SD) were studied. All of the sheep were initially given pentothal $(30 \mathrm{mg} / \mathrm{kg})$, intubated, and ventilated with a constant-volume pump (Harvard, 
Millis, MA) at a tidal volume of $400-500 \mathrm{ml}(13-15 \mathrm{ml} / \mathrm{kg}$ ) with a peak inspiratory pressure of $15-20 \mathrm{~cm} \mathrm{H}_{2} \mathrm{O}$ and a positive end-expiratory pressure of $5 \mathrm{~cm} \mathrm{H}_{2} \mathrm{O}$. The respiratory rate was adjusted to achieve a $\mathrm{PaCO}_{2}$ between 30 and $40 \mathrm{mmHg}$. Anesthesia was maintained with $1.0-1.5 \%$ halothane mixed with supplemental oxygen (40-60\%). Of the 47 sheep, 30 remained anesthetized for the duration of the experiment, and were then exsanguinated at the termination of the experiment. The remaining 17 sheep were allowed to recover from anesthesia, and were extubated when they were awake and spontaneously breathing. They remained unanesthetized for $24 \mathrm{~h}$ and then were given intravenous ketamine $(10 \mathrm{mg} / \mathrm{kg})$ and exsanguinated.

The 30 sheep that remained anesthetized had vascular catheters inserted to measure pulmonary and systemic hemodynamics. All 30 sheep had catheters inserted via a right thoracotomy into the efferent duct of the caudial mediastinal lymph node to measure lung lymph flow. The preparative surgery required $1.5-2 \mathrm{~h}$ and then the 30 anesthetized sheep were placed in a prone position with their head and thorax elevated at a $5^{\circ}$ angle. All transducers (PD-23 ID transducers; Gould Inc., Oxnard, CA) were zeroed to midchest level.

The 17 sheep that were studied for $24 \mathrm{~h}$ had carotid arterial and external jugular venous catheters inserted while anesthetized. Of these 17 sheep, four had lung lymph catheters. All 17 spontaneously breathing sheep were placed in a metabolic cart, with free access to food and water.

All experiments were done in compliance with the UCSF Animal Care Committee rules and all protocols were approved.

\section{Preparation of serum instillate}

Autologous serum was used as the instillate in 35 experiments. In these studies, the sheep had $250 \mathrm{ml}$ of blood drawn the day before the experiment to prepare autologous serum. The blood was withdrawn using sterile technique, clotted, and centrifuged to obtain serum. The serum was refrigerated overnight and the next morning $20 \mathrm{mg}$ of anhydrous Evan's blue and $20 \mu \mathrm{Ci}$ of ${ }^{125} \mathrm{I}$-albumin-labeled human serum albumin (Merck-Frosst, Quebec, Canada) were added to the sheep's serum, as we have done in prior studies $(7,8)$. Evan's blue was used to be certain that the instilled serum was confined to the instilled lower lobe. We saved a sample of the labeled serum for total protein measurements and wet/dry ratio measurements so that we could subtract the dry weight of the serum from the final lung water calculation. In the 35 experiments in which serum was instilled into one caudal lobe, $3 \mathrm{ml} / \mathrm{kg}$ of serum was instilled.

We chose autologous serum as our primary instillate for several reasons. Previously, we have compared heparinized plasma, autologous serum, and 5\% ovine albumin in Ringers lactate and found that all three were comparable in terms of the quantity of plasma and leukocyte influx into the air spaces (8). Furthermore, E. coli endotoxin is only a modest neutrophil stimulus in vitro in the absence of serum and the presence of plasma has been shown to be necessary for optimal neutrophilic degranulation and superoxide generation (9). Also, endothelial cell injury is potentiated in vitro by the presence of serum, possibly because of complement activation (10). Therefore, we used serum as the primary instillate to maximize the injury from $E$. coli endotoxin.

Although serum was used as the instillate in the majority of the experiments, three experiments were also done over $24 \mathrm{~h}$ with $E$. coli endotoxin $(100 \mu \mathrm{g} / \mathrm{kg})$ added to $5 \%$ ovine albumin dissolved in Ringer's lactate $(3 \mathrm{ml} / \mathrm{kg})$ to investigate the effect of $E$. coli endotoxin in the airspaces without the presence of serum or plasma factors. Also, the four positive control studies with alveolar Pseudomonas aeruginosa over $24 \mathrm{~h}$ (see below) were done in 5\% ovine albumin dissolved in Ringer's lactate.

\section{Alveolar liquid sampling and time course of experiments}

To obtain a sample of alveolar liquid from the serum-instilled lung at the end of the experiment after removal of the lungs, we obtained 2-5 $\mathrm{ml}$ of alveolar liquid by passing a 3-mm-diameter catheter into the distal airways as we have done before $(7,11)$. A total and differential leukocyte cell count was done on this alveolar liquid sample; then, the sample was centrifuged and the total protein concentration and radioactivity of the alveolar liquid sample was measured. In a prior study, we reported that the concentration of the native protein in the liquid sampled by a 3-mm catheter wedged into the distal airways was the same as in a directly obtained alveolar micropuncture sample (11).

Alveolar liquid sampling was done at the end of the 4- and 24-h experiments after the lungs were removed. These time intervals were selected for several reasons. First, our prior experiments in normal sheep indicated that by $4 \mathrm{~h} \sim 30 \%$ of the instilled liquid volume was removed from the air spaces and the lung, whereas only 5-6\% of the instilled alveolar protein tracer was removed $(7,8)$. Also, only a small quantity of circulating plasma enters the air spaces in the normal sheep lung over $4 \mathrm{~h}(7,8)$. Thus, we reasoned that the 4 -h time interval would be useful for detecting significant early changes in bidirectional flux of the alveolar and vascular protein tracers across the epithelium. The 4-h protocol was designed so that the intravenous $E$. coli endotoxin was given $2 \mathrm{~h}$ before serum instillation so that the alveolar test solution would be present in the air spaces 2-6 h after $E$. coli endotoxin was infused during the period when increased lung endothelial permeability is usually maximal in sheep (6). Also, we wanted to examine an early time interval in the high-dose alveolar $E$. coli endotoxin studies to be certain that we maximized the opportunity to measure a change in epithelial permeability to protein shortly after $E$. coli endotoxin had chemoattracted large numbers of neutrophils to the air spaces of the lung.

The longer time interval, $24 \mathrm{~h}$, was selected to examine the effects of $E$. coli endotoxin beyond the acute phase in sheep that were spontaneously ventilating without anesthesia or recent surgery. Also, our prior studies in normal sheep over $24 \mathrm{~h}$ also established that by $24 \mathrm{~h} \sim 75 \%$ of the liquid volume of the instilled serum was removed from the air spaces and the lung, whereas only $25 \%$ of the alveolar protein tracer is normally cleared $24 \mathrm{~h} \mathrm{(8)}$. Thus, these 24 -h studies would be completed well before the $T 1 / 2$ for normal alveolar protein clearance $(40 \pm 6 \mathrm{~h})$ was reached (12), and a later alteration in epithelial protein permeability could be detected, as in fact was the case in the positive control studies over $24 \mathrm{~h}$ with alveolar Pseudomonas aeruginosa (see Results).

\section{Specific protocols}

Control sheep with serum instillation alone $(n=10)$. We studied six anesthetized sheep for $4 \mathrm{~h}$ and four unanesthetized sheep for $24 \mathrm{~h}$. On the day of the experiment, the six anesthetized sheep were surgically prepared, as described above, including placement of a lung lymph cannula. Lymph flow was measured for a 1-h stable baseline period, before human ${ }^{131} \mathrm{I}$-albumin (Merck-Frosst) was injected intravenously. Then the autologous serum was instilled into either a right or left caudal lobe of the sheep using a fiberoptic bronchoscope (Machida America, Inc., Norwood, NJ). By using a three-way t-piece adapter on the endotracheal tube, we maintained ventilation during bronchoscopy. Systemic, pulmonary, and left atrial pressures, cardiac output, and lung lymph were measured every $15 \mathrm{~min}$. Blood and lymph samples were taken every $30 \mathrm{~min}$ for total protein concentration measurements and for ${ }^{125} \mathrm{I}$-albumin and ${ }^{131} \mathrm{I}$-albumin counts. After $4 \mathrm{~h}$, the sheep were exsanguinated and the lungs were removed for sampling of alveolar liquid. This final alveolar liquid sample was counted for ${ }^{125}$ I-albumin that remained in the air spaces from the blood; the total protein concentration and the number of leukocytes was also determined. Extravascular lung water was measured on both lungs separately (see Measurements).

After anesthesia and intubation, the four other control sheep to be studied for $24 \mathrm{~h}$ underwent instillation of autologous serum into a caudal lobe using the bronchoscope. These four sheep also received ${ }^{131}$ I-albumin intravenously. The sheep were then allowed to awaken, extubated when breathing normally, and then placed in a metabolic cart for $24 \mathrm{~h}$. After this interval, the sheep were anesthetized, exsanguinated, and processed as in the 4-h experiments.

Group 1: intravenous endotoxin with raised left atrial pressure ( $n$ $=5$ ). In all of these sheep, no autologous serum was prepared. After $1 \mathrm{~h}$ of stable lymph flow, four sheep received $5 \mu \mathrm{g} / \mathrm{kg}$ of $E$. coli endotoxin 
(DIFCO) intravenously over $30 \mathrm{~min}$. The hemodynamic pressures and lymph flow were monitored as described for $6 \mathrm{~h}$. During this time period, the sheep received Ringer's lactate solution to maintain a mean left atrial pressure above $12 \mathrm{~cm} \mathrm{H}_{2} \mathrm{O}$. Left atrial pressure was elevated to increase the possibility of developing alveolar edema. After $6 \mathrm{~h}$, the sheep were exsanguinated and their lungs were removed for extravascular lung water determination (see Measurements). One additional sheep received $50 \mu \mathrm{g} / \mathrm{kg}$ of intravenous $E$. coli endotoxin plus lactated Ringer's solution to evaluate the effects of a large dose of $E$. coli endotoxin on the formation of alveolar edema. This sheep was followed as the other four sheep had been and was processed similarly.

Group 2: intravenous endotoxin with serum instillate $(n=5)$. Five sheep had their blood drawn for preparation of autologous serum. After $1 \mathrm{~h}$ of stable baseline measurements, three sheep received ${ }^{131} \mathrm{I}$-albumin and $5 \mu \mathrm{g} / \mathrm{kg}$ of $E$. coli endotoxin intravenously over $30 \mathrm{~min}$; the other two sheep received $500 \mu \mathrm{g} / \mathrm{kg}$ of $E$. coli endotoxin intravenously over $30 \mathrm{~min}$. Systemic and pulmonary hemodynamics and lung lymph flow were measured, as in the control experiments. $2 \mathrm{~h}$ after the administration of $E$. coli endotoxin, autologous serum, labeled with the Evans blue dye and ${ }^{125} \mathrm{I}$-albumin, was instilled into one caudal lobe. The sheep were then followed for $4 \mathrm{~h}$, exsanguinated, and processed as described.

Group 3: intravenous and low-dose alveolar endotoxin with serum instillate $(n=3)$. These sheep also had their blood drawn for preparation of autologous serum. After $1 \mathrm{~h}$ of stable lymph flow, the sheep received ${ }^{131} \mathrm{I}$-albumin and $5 \mu \mathrm{g} / \mathrm{kg}$ of $E$. coli endotoxin intravenously over $30 \mathrm{~min} .2 \mathrm{~h}$ after the administration of the intravenous $E$. coli endotoxin, $10 \mu \mathrm{g} / \mathrm{kg}$ of $E$. coli endotoxin was added to the autologous serum along with the Evans blue dye and ${ }^{125} \mathrm{I}$-albumin, which were then instilled into one caudal lobe. The sheep were then followed for 4 $\mathrm{h}$ and processed as described above.

Group 4: high-dose alveolar endotoxin with serum instillation (n $=12$ ). The effect of instillation of high dose $E$. coli endotoxin into the air spaces was examined in 12 sheep. Six sheep were studied for $4 \mathrm{~h}$ (three sheep received $50 \mu \mathrm{g} / \mathrm{kg} E$. coli endotoxin and three sheep had $100 \mu \mathrm{g} / \mathrm{kg}$ of endotoxin added to the instilled autologous serum). The remaining six sheep were studied for $24 \mathrm{~h}$, all six of these sheep had 100 $\mu \mathrm{g} / \mathrm{kg}$ of $E$. coli endotoxin added to the instilled autologous serum. The serum was prepared and instilled as described in the control serum alone experiments. All sheep received ${ }^{131} \mathrm{I}$-albumin intravenously as a plasma marker. Two of the six sheep who were studied for $24 \mathrm{~h}$ had lung lymph fistula placed during sterile surgery $1 \mathrm{wk}$ before the experiments. The six sheep studied for $24 \mathrm{~h}$ were allowed to awaken; the other six sheep remained anesthetized and were studied as previously described. All 12 sheep were handled as described for the control serum alone experiments.

Group 5: intravenous oleic acid $(n=3)$ and left atrial hypertension $(n=2)$. To provide positive controls over $4 \mathrm{~h}$ for an injury delivered by the bloodstream, oleic acid $(0.8-0.12 \mathrm{ml} / \mathrm{kg}$ ) (Sigma Chemical Co., St. Louis, MO) was given, as we have done in prior studies (13), $15 \mathrm{~min}$ after the instillation of autologous serum $(3 \mathrm{ml} / \mathrm{kg}$ ) into one lower lobe with the same protocol for labeling of the vascular and alveolar spaces with ${ }^{131} \mathrm{I}$-albumin and ${ }^{125} \mathrm{I}$-albumin, respectively, and removing the lung after $4 \mathrm{~h}$, sampling the alveolar space, and processing the lungs as described.

Because oleic acid was associated with an alteration in epithelial permeability to protein, we thought it was important to include controls for the elevation of pulmonary vascular pressure that occurred in the oleic acid experiments. There was a mean increase of $7 \mathrm{~cm} \mathrm{H}_{2} \mathrm{O}$ in the calculated pulmonary microvascular pressure in the oleic acid studies, based primarily on a rise in pulmonary arterial pressure. Therefore, we studied two sheep in which left atrial pressure was increased by $7 \mathrm{~cm}$ $\mathrm{H}_{2} \mathrm{O}$ with a left atrial balloon, as we have done before (14), and then instilled serum into one lower lobe. The same variables were measured as in the other experiments.

Group 6: alveolar Pseudomonas aeruginosa $(n=4)$ and additional alveolar endotoxin studies $(n=3)$. To provide positive controls over 24 $\mathrm{h}$ for an injury delivered from the air space side of the epithelial barrier, live Pseudomonas aeruginosa bacteria $\left(4 \pm 3 \times 10^{9}\right)$ were instilled with
$5 \%$ ovine albumin in Ringer's lactate $(3 \mathrm{ml} / \mathrm{kg})$ and the sheep were studied and the lungs processed as in the other 24-h experiments. Also, in order to provide additional data regarding the effect of using an instillate other than serum, we did three additional 24-h studies in which $E$. coli endotoxin was instilled in a 5\% albumin and Ringer's lactate solution to be certain that the serum did not inhibit an injurious effect of endotoxin on the epithelial barrier.

\section{Measurements of hemodynamics and protein concentration}

Systemic arterial, pulmonary arterial, left atrial, and airway pressures as well as cardiac output by thermodilution (model 3500; Mansfield Scientific, Mansfield, MA) were measured at 15-min intervals in all anesthetized sheep. Arterial blood gases were measured hourly. The total protein concentration of plasma, lymph, instilled, and final samples from the air spaces were measured using an automated analyzer (AAII; Technicon, Tarrytown, NJ). Albumin concentration was determined by the bromocresol green-binding method.

\section{Alveolar epithelial barrier protein permeability}

Two different methods were used to measure the bidirectional flux of albumin across the alveolar epithelial barrier $(7,8,11)$. The first method required measurement of the residual ${ }^{125}$ I-albumin (the alveolar protein tracer) in the lung as well as the accumulation of ${ }^{125} \mathrm{I}$-albumin in the plasma. The second method required measurement of ${ }^{131} \mathrm{I}-$ albumin (the vascular protein tracer) in the air space compartment of the lung.

The total quantity of ${ }^{125} \mathrm{I}$-albumin (the alveolar protein tracer) instilled into the lung was determined by measuring duplicate samples of the instilled serum for total counts ( $\mathrm{cpm} / \mathrm{g}$ ) and then multiplying this data by the total volume instilled into the lung. To calculate the residual ${ }^{125} \mathrm{I}$-albumin in the lung after 4 or $24 \mathrm{~h}$, the average of two $0.5 \mathrm{-g}$ samples obtained from the lung homogenate (see below) was multiplied by the total volume of the lung homogenate. The lung homogenate data was added to the recovered counts in the aspirated alveolar fluid to provide the data for the recovery of the instilled ${ }^{125} \mathrm{I}$-albumin remaining in the lung after 4 or $24 \mathrm{~h}$. The ${ }^{125}$ I-albumin in the circulating plasma was measured from a sample of plasma obtained at the end of the experiment. The plasma fraction was accounted for by multiplying the counts per milliliter times the plasma volume (body weight $\times 0.07[1-\mathrm{Hct}])$.

The early appearance of the alveolar protein $\operatorname{tracer}\left({ }^{125} \mathrm{I}\right.$-albumin $)$ in the lymph and plasma was examined hourly in the 4-h experiments to detect a change in the rate of appearance of the alveolar protein tracer in either the lung interstitium (i.e., lymph) or the vascular space.

The second method required measurement of the vascular protein tracer, ${ }^{131} \mathrm{I}$-albumin, in the final alveolar liquid sample. Then, the ${ }^{131} \mathrm{I}$ albumin counts in the plasma over the course of the experiment were averaged, and the ${ }^{131} \mathrm{I}$-albumin counts in the air spaces were expressed as a ratio to the plasma counts. This ratio provides a good index of equilibration of the vascular protein tracer into the alveolar compartment, as other investigators have shown in prior experimental studies of epithelial permeability (15).

Also, the accumulation of the vascular protein tracer in the extravascular space of the lung as a whole was used as an additional index of endothelial permeability. In the experiments with intravenous endotoxin, left atrial hypertension, and controls, the extravascular accumulation of ${ }^{131} \mathrm{I}$-albumin was used in the 4-h studies to measure the endothelial permeability in addition to the changes in lung lymph flow. The accumulation of the vascular protein tracer, ${ }^{131} \mathrm{I}$-albumin, is expressed as milliliters and is calculated by determining the total extravascular counts of ${ }^{131} \mathrm{I}$-albumin in the lung divided by the average counts in the plasma over $4 \mathrm{~h}$.

\section{Estimate of alveolar liquid (solute) clearance}

As in our prior studies, alveolar liquid (solute) clearance was estimated by measuring the increase in the total protein concentration of the instilled serum or $5 \%$ ovine albumin over 4 or $24 \mathrm{~h}(7,11)$. This increase in alveolar total protein concentration provides a good estimate 
of the quantity of liquid that has been removed from the air spaces of the lung, as we have established in several prior experimental studies (7, 8,11 ), providing there has not been a major injury to the epithelium Thus, in the positive control studies with oleic acid over $4 \mathrm{~h}$, alveolar volume cannot be accurately estimated; however, if the protein in the instilled serum protein does not concentrate or is diluted, then this provides additional evidence for injury to the epithelial barrier. When injury to the epithelium is less severe, as in the 24-h positive control studies with Pseudomonas, it would be expected that the instilled alveolar protein would not concentrate as much as in the control studies, partly because of a greater loss of protein from the air spaces of the lung. In this circumstance, the alveolar protein concentration should not be used to make an estimate of alveolar liquid clearance because the calculation would include too much uncertainty regarding the quantity of instilled protein that had escaped from the air spaces.

\section{Lung liquid clearance (extravascular lung water measurement)}

After each experiment, we obtained a 40-ml blood sample to measure hemoglobin concentration and the wet/dry ratio of blood for the extravascular lung water calculation (16). The lungs were removed from the thorax and after an alveolar liquid sample was obtained from the serum-instilled lung, the lungs were frozen in liquid nitrogen. The next day, each lung was examined in a cryostat at $-20^{\circ}$ to determine the distribution of the Evans blue-labeled serum. We then homogenized each lung separately and determined the extravascular lung water.

We used two methods for expressing the wet/dry weight ratio data, depending on the experimental protocol. For example, for the five sheep in group 1 who received intravenous $E$. coli endotoxin and crystalloid solution, we made the calculation directly for each lung. For the remaining 42 sheep who had serum or $5 \%$ albumin with Ringer's lactate instilled into one lung, the excess water in the instilled experimental lung was calculated as the difference between the wet-to-dry weight ratios of the experimental and contralateral control lung times the dry weight of the experimental lung. The dry weight of the serum-instilled lung was corrected for the dry weight of the instilled protein remaining in the lung at the end of the experiment. To determine the mass of protein remaining, the dry weight of the instillate was multiplied by the fraction of ${ }^{125} \mathrm{I}$-albumin remaining in the lung. This value was then subtracted from the total dry weight of the experimental lung. The equation is $E=\left[W_{\mathrm{e}} /\left(D_{\mathrm{e}}-P\right)-W_{\mathrm{c}} / D_{\mathrm{c}}\right] \times\left(D_{\mathrm{e}}-P\right)$, where $E$ is the excess water in the experimental lung, $W$ and $D$ are wet and dry weights of the contralateral control (c) and experimental (e) lungs, and $P$ is the weight of the protein instilled into the lung multiplied by the fraction of ${ }^{125} \mathrm{I}-\mathrm{al}-$ bumin left in the lung (11). The excess water was then used to calculate the percent of lung liquid clearance by subtracting the excess water after 4 or $24 \mathrm{~h}$ from the volume of water instilled divided by the total volume instilled. In previous control studies, we found that the method was accurate for recovering instilled volume; the method has a coefficient of variation of $11 \%(7,8)$. This method can also be used for the oleic acid injury experiments (group 5) because the injury should be equally severe in both lungs, as we have reported before (13). The calculation of the blood volume with hemoglobin after oleic acid results in a modest underestimate of extravascular lung water because oleic acid causes hemolysis but this effect should be similar in the two lungs. However, in the presence of severe injury, as with oleic acid, the accuracy of the lung liquid clearance calculation is likely to be less than in normal lungs or in the presence of mild to moderate lung injury.

\section{Lung morphology}

For the group 1 sheep, the extent of extravascular lung water was evaluated morphologically with the following methods. After the lungs were removed, they were inflated to $20 \mathrm{~cm} \mathrm{H}_{2} \mathrm{O}$ and immersed in liquid nitrogen. Then, the next day, the frozen lung specimens $\left(2 \mathrm{~cm}^{3}\right)$ were examined in a $-20^{\circ} \mathrm{C}$ cryostat. We evaluated tissue blocks for the presence of interstitial fluid cuffs and flooding of the air spaces. This morphologic method has an excellent correlation with independent measurements of extravascular lung water (17).
For groups 2-4, we evaluated lung morphology in the 4-h anesthetized sheep experiments in four sheep from each group. The observer (KA) did not know the nature of the experiment at the time of the initial morphologic observations. Lung biopsies were obtained by a double clamping procedure, whereby a free margin $(2 \times 5 \mathrm{~cm})$ of the right or left caudal lobe was excised. Fixative (2\% glutaraldehyde-1\% paraformaldehyde in Millong's phosphate buffer, pH 7.45, 320 mosmol) was injected at several locations along the lung biopsy, immediately after which it was immersed in fresh fixative. Several tissue samples were taken from each biopsy for both light microscopy and transmission electron microscopy. The tissue for light microscopy was dehydrated through a graded ethanol series and embedded in glycol methacrylate (Polysciences, Inc., Warrington, PA). Random 2- $\mu \mathrm{m}$ thick sections were cut from all embedded blocks and stained with $1 \%$ toluidine blue (18). For transmission electron microscopy, the lung samples $(0.5 \times 1 \times 1 \mathrm{~mm})$ were postfixed in $1 \%$ osmium tetroxide, en bloc stained with $4 \%$ uranyl acetate, dehydrated through a graded series of acetone, and embedded in Polybed 812 (Polysciences, Inc.). Random thin sections $(80 \mathrm{~mm})$ were cut from all embedded blocks with a diamond knife and counterstained with uranyl acetate and lead citrate (18). A Zeiss Axioplan light microscope was used for photomicroscopy and an Hitachi H-7000 was used for transmission electron microscopy.

\section{Statistics}

All data are presented as mean \pm SD. The hemodynamic, lymph flow, protein concentrations, lung liquid clearance, and radioactivity data in groups 2-6 were compared with the serum alone controls and to each other by analysis of variance. A Fisher's exact test was used to test for significance between groups. We accepted a $P<0.05$ as statistically significant (19).

\section{Results}

The group 1 sheep received intravenous $E$. coli endotoxin (5 $\mu \mathrm{g} / \mathrm{kg}$ ) plus sufficient intravenous crystalloid solution $(3,075 \pm 2,299 \mathrm{ml})$ to maintain a left atrial pressure of $17 \pm 5 \mathrm{~cm}$ $\mathrm{H}_{2} \mathrm{O}$ for the $6 \mathrm{~h}$ after the administration of the intravenous $E$. coli endotoxin. In all sheep, the well-described hemodynamic response to intravenous $E$. coli endotoxin occurred with an initial brisk rise in pulmonary arterial pressure followed by a substantial increase in pulmonary vascular resistance over the 6-h time interval. Lung lymph flow rose in all sheep with a marked increased in lymph protein clearance over $6 \mathrm{~h}$. Alveolar edema could not be aspirated from the air spaces when the lungs were removed after $6 \mathrm{~h}$. Also, examination of the frozen lungs in a cryostat revealed only interstitial fluid cuffs without evidence of edema in the air spaces of the lung. Extravascular lung water was $4.6 \pm 0.8 \mathrm{~g}$ water/g dry weight which was significantly higher than the value of $3.8 \pm 0.2 \mathrm{~g}$ water $/ \mathrm{g}$ dry weight $(P$ $<0.05$ ) for the lungs of the 10 control sheep. This $21 \%$ increase in extravascular lung water was consistent with the conclusion that only interstitial pulmonary edema was present in these group 1 sheep.

For the rest of the results, the data are organized to demonstrate the effects of $E$. coli endotoxin in the groups 2-4 studies on $(a)$ lung endothelial permeability, $(b)$ lung epithelial permeability, $(c)$ alveolar and lung liquid clearance, and $(d)$ the cellular response in the air spaces of the lung. In each instance, the results are compared with the control sheep that had serum alone instilled into one lobe. Also, the data for the group 2 (intravenous $E$. coli endotoxin) and the group 3 (intravenous $E$. coli endotoxin plus low dose alveolar $E$. coli endotoxin) experiments have been combined because there were no signifcant differences between the results from the two groups. The 
Table I. Effects of Intravenous and Alveolar E. coli Endotoxin on Lung Lymph Dynamics over $4 h$

\begin{tabular}{|c|c|c|c|c|}
\hline \multirow[b]{2}{*}{ Condition } & \multicolumn{3}{|c|}{ Lymph flow } & \multirow[b]{2}{*}{$\begin{array}{l}\text { Lung Lymph } \\
\text { Protein Clearance }\end{array}$} \\
\hline & No. & Baseline & $\begin{array}{l}\text { After Serum } \\
\text { Instillation }\end{array}$ & \\
\hline & & $\mathrm{ml} / \mathrm{h}$ & $\mathrm{ml} / \mathrm{h}$ & $\mathrm{ml} / \mathrm{h}$ \\
\hline \multicolumn{5}{|l|}{ Control sheep } \\
\hline Serum alone & $6^{8}$ & $4.4 \pm 2.4$ & $7.3 \pm 4.8^{*}$ & $4.4 \pm 2.2$ \\
\hline \multicolumn{5}{|l|}{ Group 2 (IV Endo) \& } \\
\hline Endo) & $8^{\S}$ & $6.6 \pm 5.5$ & $14.2 \pm 3.3^{* \neq}$ & $8.7 \pm 2.0^{\ddagger}$ \\
\hline Group 4 (Alv Endo) & $6^{8}$ & $4.8 \pm 1.7$ & $7.5 \pm 2.8^{*}$ & $4.8 \pm 0.2$ \\
\hline
\end{tabular}

Data as mean \pm SD. ${ }^{*} P<.05$ compared to baseline. ${ }^{\ddagger} P<.05$ compared to lymph flow changes after serum instillation in control and alveolar endotoxin $(100 \mu \mathrm{g} / \mathrm{kg})$ studies. ${ }^{8} \mathrm{Lymph}$ flow available in $5 / 6$ control sheep and in $6 / 8$ group 2 and 3 sheep.

group 5 experiments with oleic acid are included as positive controls for the 4-h endotoxin studies, and the group 6 experiments with alveolar Pseudomonas aeruginosa are included as positive controls for the 24-h endotoxin studies.

Lung endothelial permeability. In the control sheep with serum alone as the instillate, the lymph always increased with a decline in the lymph/plasma protein concentration ratio (Table I). In prior studies, we have reported that this small increase in lung lymph flow reflects both absorption of the excess alveolar liquid and local changes in microvascular filtration produced by protein in the air spaces of the lung $(12,20)$.

In the group 2 and 3 experiments in which $E$. coli endotoxin was administered intravenously alone $(5-500 \mu \mathrm{g} / \mathrm{kg})$ or in combination with low-dose alveolar $E$. coli endotoxin, there was a significant increase in lung lymph protein clearance compared to control sheep (Table I).

To be certain that the increase in lung lymph flow in the intravenous endotoxin studies reflected a real increase in lung vascular permeability and not just a hemodynamic effect, we calculated the extravascular accumulation of the vascular protein tracer ( ${ }^{131} \mathrm{I}$-albumin) as plasma equivalents (milliliters). In the group 2 and 3 studies with intravenous endotoxin, the mean accumulation of plasma equivalents was $29 \pm 19 \mathrm{ml} / \mathrm{lung}$ compared with only $2 \pm 2 \mathrm{ml} / \mathrm{lung}$ in the control experiments and $2 \pm 1 \mathrm{ml} / \mathrm{lung}$ in the two left atrial hypertension studies.

In the group 4 experiments with high dose alveolar $E$. coli endotoxin, there was no change in lung lymph flow or lung lymph protein clearance compared to control studies over $4 \mathrm{~h}$ (Table I). In addition, the effect of high dose alveolar $E$. coli endotoxin $(100 \mu \mathrm{g} / \mathrm{kg})$ was examined in two sheep with lung lymph flow over $24 \mathrm{~h}$. Lymph flow increased from a baseline flow of $5.6 \pm 1.8$ to $9.4 \pm 3.1 \mathrm{ml} / \mathrm{h}$, but this result is similar to our recently published data on the effect of serum alone on lung
Table II. Effect of Intravenous and Alveolar E. coli Endotoxin on Bidirectional Protein Permeability across the Alveolar Epithelial Barrier over $4 \mathrm{~h}$

\begin{tabular}{|c|c|c|c|c|}
\hline Condition & No. & $\begin{array}{l}{ }^{125} \text { I-Albumin } \\
\text { in lung }\end{array}$ & $\begin{array}{l}{ }^{125} \text { I-Albumin } \\
\text { in blood }\end{array}$ & $\begin{array}{l}\text { Alveolar fluid/ } \\
\text { plasma } \\
{ }^{131} \text { I-albumin }\end{array}$ \\
\hline & \multicolumn{3}{|c|}{ \% instilled } & \\
\hline \multicolumn{5}{|l|}{ Control sheep } \\
\hline Serum alone & 6 & $93 \pm 7$ & $2 \pm 2$ & $0.10 \pm 0.08$ \\
\hline \multicolumn{5}{|c|}{$\begin{array}{c}\text { Group } 2 \text { (IV Endo) and } \\
\text { Group } 3 \text { (IV + Alv }\end{array}$} \\
\hline Endo) & 8 & $95 \pm 6$ & $1 \pm 2$ & $0.08 \pm 0.0$ \\
\hline Group 4 (Alv Endo) & 6 & $95 \pm 5$ & $1 \pm 1$ & $0.16 \pm 0.03$ \\
\hline Group 5 (oleic acid) & 3 & $89 \pm 1^{*}$ & $4 \pm 2 *$ & $0.67 \pm 0.06^{*}$ \\
\hline
\end{tabular}

Data shown as mean $\pm \mathrm{SD} .^{*} P<0.05$ compared to other groups.

lymph flow over $24 \mathrm{~h}$ (12). Thus, high doses of alveolar $E$. coli endotoxin had no significant effect on lung endothelial permeability.

Lung epithelial protein permeability. There was no significant effect of $E$. coli endotoxin in the 4-h studies on the removal of the alveolar protein tracer, ${ }^{125} \mathrm{I}$-albumin, from the lung compared with the control studies (Table II). Also, the accumulation of the vascular protein tracer, ${ }^{131}$ I-albumin, across the epithelium into the air spaces was not significantly altered in the 4-h $E$. coli endotoxin studies (Table II). The mean accumulation of the vascular tracer in the alveolar endotoxin studies was slightly higher than controls but did not reach statistical significance. In contrast, in the oleic acid experiments, there was a significant fourfold increase in the accumulation of the vascular protein tracer, ${ }^{131}$ I-albumin, in the air spaces over $4 \mathrm{~h}$ (Table II). Oleic acid also resulted in a small but significant increase in the clearance of the alveolar tracer, ${ }^{125} \mathrm{I}$ albumin, into the blood with a correspondingly significant reduced recovery of the ${ }^{125} \mathrm{I}$-albumin tracer in the lung (Table II).

To provide a control for the modest microvascular pressure elevation with oleic acid, we performed two studies with left atrial hypertension over $4 \mathrm{~h}$. There was no effect on the clearance of the alveolar tracer. The ratio of the vascular tracer in the alveolar fluid compared to the plasma after $4 \mathrm{~h}$ was $0.15 \pm 0.04$, similar to the serum control experiments and the endotoxin studies.

The morphologic studies confirmed the physiologic data. Although there was morphologic evidence of lung endothelial injury when $E$. coli endotoxin was given intravenously, there was no evidence of alveolar epithelial cell or barrier injury in these 4-h studies (Fig. 1, $A$ and $B$ ). We and others have reported morphologic evidence of endothelial and epithelial injury with oleic acid injury in sheep $(13,21)$.

Figure 1. Ultrastructural appearance of lung taken $4 \mathrm{~h}$ after instillation of autologous serum and the intravenous infusion of $5 \mu \mathrm{g} / \mathrm{kg} E$. coli endotoxin in one sheep $(A)$ compared with ultrastructural appearance of lung taken $\mathbf{4} \mathrm{h}$ after the instillation of serum with alveolar endotoxin $(100 \mu \mathrm{g} / \mathrm{kg})(B)$. (A) Air spaces $(A)$ are filled with instilled serum. The endothelial cells $(E N)$ and interstitial cells $(I C)$ have developed numerous pinocytotic vesicles (arrow). In contrast, alveolar epithelial cells $(E P)$ retained their normal pale staining characteristics and did not have increased numbers of pinocytotic vesicles (arrows). $(B)$ The air spaces $(A)$ are filled with serum and intraalveolar endotoxin. Note increased numbers of pinocytotic vesicles (arrows) in alveolar capillary $(c)$ endothelial cells $(E N)$. Alveolar epithelial cell $(E P)$ ultrastructure was not affected by instilled E. coli endotoxin. 

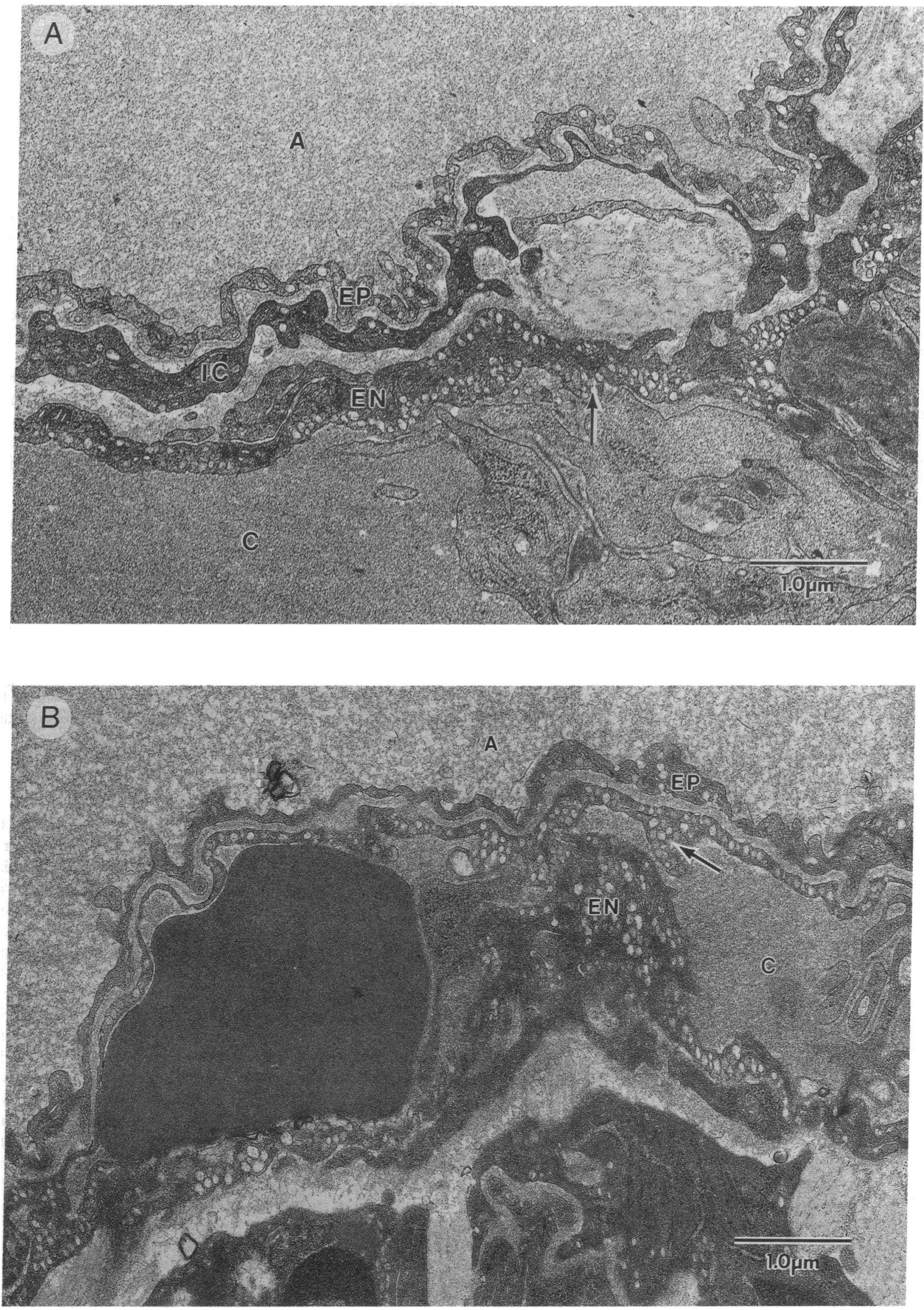
In the 24-h studies, there was no effect of high-dose alveolar $E$. coli endotoxin on the movement across the alveolar epithelial barrier of either the alveolar ( ${ }^{125} \mathrm{I}$-albumin) or the vascular ( ${ }^{131} \mathrm{I}$-albumin) protein tracer (Table III). The instillation of alveolar endotoxin in 5\% albumin and Ringer's lactate instead of in serum resulted in no change in clearance of the vascular or alveolar protein tracers across the epithelium. The quantity of ${ }^{125} \mathrm{I}$-albumin in the blood was $8 \pm 4$ (percent of instilled alveolar tracer $)(n=3)$ and the ratio of the vascular tracer, ${ }^{131} \mathrm{I}$-albumin, in the air spaces to the plasma concentration after $24 \mathrm{~h}$ was $0.18 \pm 0.02$. In contrast, with live Pseudomonas aeruginosa bacteria in the air spaces (group 6), there was a significant increase in the clearance of the alveolar protein tracer from the lung and into the blood after $24 \mathrm{~h}$ (Table III). Also, the accumulation of the vascular protein tracer into the air spaces was significantly increased compared with the serum control experiments or the alveolar endotoxin experiments.

Alveolar and lung liquid clearance. Alveolar liquid clearance, as estimated by the concentration of the instilled native protein, was similar in the control and all the endotoxin experiments over $4 \mathrm{~h}$ (Table IV). In the oleic acid studies, the final alveolar protein concentration declined, indicating that the instilled serum was diluted by the influx of circulating plasma, as confirmed by the fourfold increase in the vascular protein tracer concentration in the air spaces (Table II). Because there was a marked change in epithelial protein permeability, the alveolar volume cannot be estimated by comparing the final to the initial protein concentration. However, calculation of lung liquid clearance based on the total excess liquid volume in the serum-instilled versus the contralateral lung suggested that there was no net clearance of the instilled serum from the lung in the oleic acid experiments, whereas lung liquid clearance was normal in all the studies with endotoxin (Table IV).

In the 24-h studies, alveolar and lung liquid clearance with alveolar endotoxin were similar to the control studies with serum alone. Also, there were no pleural effusions found in the 24-h endotoxin studies. However, with alveolar Pseudomonas aeruginosa, there was a modest $(25 \%)$ but significant decline in the calculated lung liquid clearance (Table V). Alveolar and lung liquid clearance appears to have been reduced proportionally on the basis of a $20 \%$ reduction in the magnitude of alveolar protein concentration over $24 \mathrm{~h}$ (Table V), but this estimate may be less reliable because of the more rapid clearance of the protein from the air spaces in the 24-h Pseudomonas studies, as shown in Table III.

Table III. Effect of Alveolar E. coli Endotoxin on Bidirectional Protein Permeability across the Alveolar Epithelial Barrier over $24 \mathrm{~h}$

\begin{tabular}{lcccc}
\hline \multicolumn{1}{c}{ Condition } & No. & $\begin{array}{c}\text { 125 I-Albumin } \\
\text { in lung }\end{array}$ & $\begin{array}{c}{ }^{125} \text { I-Albumin } \\
\text { in blood }\end{array}$ & $\begin{array}{c}\text { Alveolar fluid/ } \\
\text { plasma } \\
\text { 131 I-albumin }\end{array}$ \\
\hline \multicolumn{5}{c}{ \% instilled } \\
Control sheep & \multicolumn{4}{c}{} \\
$\quad$ Serum alone & 4 & $74 \pm 9$ & $8 \pm 3$ & $0.32 \pm 0.10$ \\
Group 4 (Alv Endo) & 6 & $74 \pm 8$ & $8 \pm 2$ & $0.26 \pm 0.13$ \\
Group 6 (Alv Pseudo) & 4 & $65 \pm 2^{*}$ & $12 \pm 1^{*}$ & $0.47 \pm 0.14^{*}$ \\
& & & &
\end{tabular}

Mean \pm SD. ${ }^{*} P<0.05$ compared to other groups.
Table IV. Alveolar Protein Concentrations and Lung Liquid Clearance over $4 \mathrm{~h}$

\begin{tabular}{lcccc}
\hline & & \multicolumn{2}{c}{ Alveolar protein } & \\
\cline { 3 - 4 } \multicolumn{1}{c}{ Condition } & No. & Instilled & Final & $\begin{array}{c}\text { Lung liquid } \\
\text { clearance }\end{array}$ \\
\hline & & $g / 100 \mathrm{ml}$ & \% instilled \\
Control sheep & & & & \\
$\quad$ Serum alone & 6 & $6.2 \pm 0.5$ & $7.6 \pm 0.4$ & $25 \pm 16$ \\
Group 2 (IV Endo) \& & & & & \\
$\quad$ Group 3 (IV Alv + Endo) & 8 & $6.0 \pm 0.5$ & $7.9 \pm 0.9$ & $25 \pm 19$ \\
Group 4 (Alv Endo) & 6 & $6.0 \pm 0.6$ & $7.9 \pm 1.0$ & $28 \pm 7$ \\
Group 5 (oleic acid) & 3 & $7.1 \pm 0.2$ & $5.4 \pm 1.1^{*}$ & 0 \\
& & & & \\
\hline
\end{tabular}

Mean \pm SD. ${ }^{*} P<0.05$ compared to other final protein concentrations.

Cellular response in the air spaces. Serum alone was chemotactic for leukocytes (Fig. 2), as we have previously reported (8). The addition of high doses of alveolar $E$. coli endotoxin in the 4-h studies in group 4 sheep resulted in a 10-fold increase in the number of leukocytes entering the air spaces, most of which were neutrophils (Fig. 2). However, when intravenous $E$. coli endotoxin was administered first followed by instillation of serum with or without $E$. coli endotoxin (groups 2 and 3), the number of neutrophils entering the air spaces was statistically less $(P<0.05)$ compared with the serum alone studies (Fig. 2). The light microscopy confirmed this result by demonstrating fewer intraalveolar neutrophils when $E$. coli endotoxin was given intravenously compared with the studies in which $E$. coli endotoxin was administered only in the air spaces (Fig. 3, $A$ and $B$ ). Finally, by $24 \mathrm{~h}$, there was no statistical difference between the number of leukocytes or neutrophils present in the air spaces in the high dose alveolar $E$. coli endotoxin studies compared with the serum alone studies (Fig. 4).

\section{Discussion}

The overall objective of these experiments was to examine the effect of $E$. coli endotoxin on the alveolar epithelial barrier in sheep. Although prior investigators have reported a marked increase in lung endothelial permeability in a variety of in vivo and in vitro studies with $E$. coli endotoxin, there has been very little work on the effects of $E$. coli endotoxin on the alveolar epithelium. The normally tight alveolar epithelial barrier prevents filling of the air spaces with interstitial fluid unless the capacity of the interstitial space is overwhelmed with interstitial edema fluid and/or there is injury to the epithelial barrier.

The first objective of these studies was to determine if intravenous $E$. coli endotoxin $(5 \mu \mathrm{g} / \mathrm{kg})$ in the presence of modest volume expansion (left atrial pressure, $17 \pm 5 \mathrm{~cm} \mathrm{H}_{2} \mathrm{O}$ ) would cause alveolar edema. Our data indicated that only interstitial edema developed with a $20 \%$ increase in extravascular lung water. These results are similar to data reported by Allen et al. (22) who elevated both left atrial and cranial vena caval pressure in unanesthetized sheep that had received $4 \mu \mathrm{g} / \mathrm{kg}$ of intravenous $E$. coli endotoxin. When left atrial pressure was raised to $13 \mathrm{mmHg}$ and cranial vena caval pressure to $17 \mathrm{mmHg}$, extravascular lung water increased only to $5.2 \pm 0.1 \mathrm{~g} \mathrm{H}_{2} \mathrm{O} / \mathrm{g}$ dry lung. This $25 \%$ increase in extravascular lung water also did not cause alveolar edema. 
Table V. Alveolar Protein Concentrations and Lung Liquid Clearance over $24 h$

\begin{tabular}{lcccc}
\hline & & \multicolumn{2}{c}{ Alveolar protein } & \\
\cline { 3 - 4 } \multicolumn{1}{c}{ Condition } & No. & Instilled & Final & $\begin{array}{c}\text { Lung liquid } \\
\text { clearance }\end{array}$ \\
\hline Control sheep & & & $g / 100 \mathrm{ml}$ & \% instilled \\
$\quad$ Serum alone & 4 & $6.3 \pm 0.6$ & $11.5 \pm 1.4$ & $67 \pm 14$ \\
Group 4 (Alv Endo) & 6 & $6.3 \pm 0.6$ & $11.7 \pm 3.3$ & $66 \pm 8$ \\
Group 6 (Alv Pseudo) & 4 & $6.1 \pm 0.5$ & $9.5 \pm 3.4$ & $48 \pm 4^{*}$ \\
\hline
\end{tabular}

Mean \pm SD. $* P<0.05$ compared to other lung liquid clearance data.

There is one report of intravenous $E$. coli endotoxin $(5 \mu \mathrm{g} /$ $\mathrm{kg}$ ) causing alveolar edema. Esbenshade et al. (23) infused 2-5 $\mu \mathrm{g} / \mathrm{kg}$ of $E$. coli endotoxin into 11 unanesthetized sheep over 20-60 min and then studied the sheep for 2-10 h. Only four of the 11 sheep developed alveolar edema with a postmortem extravascular lung wet/dry ratio of 6 or greater. On the other hand, Gabel et al. (24) studied unanesthetized sheep for $3 \mathrm{~h}$ after intravenously infusing $1 \mu \mathrm{g} / \mathrm{kg}$ of $E$. coli endotoxin. The average extravascular lung water ratio in these sheep was 4.5 \pm 0.6 . Likewise, investigators who have used anesthetized pigs (25) have reported that extravascular lung water increased only modestly from $4.3 \pm 0.1$ to $5.0 \pm 0.2$ after a total of $11 \mu \mathrm{g} / \mathrm{kg}$ of $E$. coli endotoxin was intravenously infused. Studies in dogs have provided similar results. For example, Welsh et al. (26) infused $4 \mu \mathrm{g} / \mathrm{kg}$ of intravenous Salmonella enteriditis endotoxin into anesthetized dogs and measured an extravascular lung water ratio of only $4.0 \pm 0.6$. Therefore, most investigators have only been able to produce interstitial edema with intravenous endotoxin.

Why does $E$. coli endotoxin not cause alveolar edema? There are two likely explanations. First, the quantity of intersti-

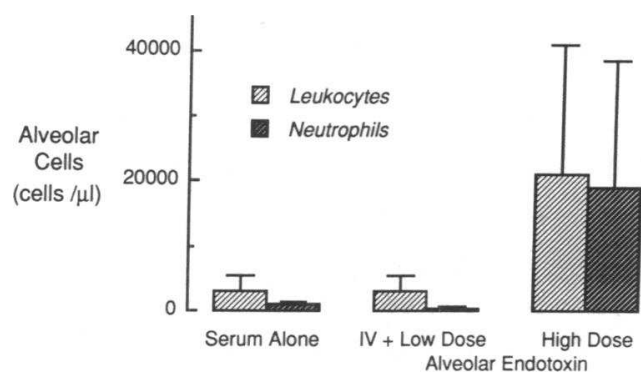

Figure 2. The number (mean $\pm \mathrm{SD}$ ) of leukocytes and neutrophils in the alveolar liquid after $4 \mathrm{~h}$ is shown for serum alone control sheep and for groups 2 and 3 (i.v. + i.v. and low-dose alveolar $E$. coli endotoxin), and group 4 (high-dose alveolar $E$. coli endotoxin). Serum alone caused some leukocytes and neutrophils to enter the alveolar liquid as we previously reported (8). Intravenous and the combination of i.v. plus low-dose alveolar $E$. coli endotoxin caused a similar influx of leukocytes into the alveolar liquid; however, the number of neutrophils entering the alveolar liquid was significantly less than in serum alone control sheep $(P<0.05)$. High-dose alveolar $E$. coli endotoxin caused the largest influx of leukocytes and neutrophils into the alveolar liquid, significantly greater compared with the other groups including the serum alone studies $(P<0.01)$. tial edema produced may be insufficient to cause an overflow phenomenon into the air spaces (27), or $E$. coli endotoxin does not alter alveolar epithelial permeability sufficiently to allow entry of interstitial edema fluid into the air spaces. Thus, the rest of our studies were designed to determine the effect of $E$. coli endotoxin on lung epithelial permeability and the capacity of the epithelium to remove excess alveolar liquid. We studied several routes for delivering $E$. coli endotoxin: intravenous, intravenous plus low-dose alveolar, and high-dose alveolar $E$. coli endotoxin over both 4 and $24 \mathrm{~h}$. There was no evidence in any of the experiments that $E$. coli endotoxin significantly altered alveolar epithelial permeability to protein or the ability of the alveolar epithelium to remove excess liquid and solutes from the air spaces. Moreover, our ultrastructural results indicated that alveolar epithelial cell structural integrity was not compromised. These coordinated structure-function analyses done in the same experiments argue against an injurious effect of $E$. coli endotoxin on the alveolar epithelium.

However, before discussing the significance of these results, it is important to consider critically our methods for measuring alveolar epithelial permeability to protein in vivo. We used albumin to test for altered epithelial barrier permeability for several reasons. Albumin has been the standard molecule for studying alterations in endothelial permeability in the lung and other organs (27). Secondly, by using ${ }^{131} \mathrm{I}$-albumin that is initially injected into the vascular space, it is possible to study endothelial and epithelial permeability to the same molecule. Third, we have studied the kinetics and mechanisms responsible for movement of albumin across the epithelial barrier of normal lungs in dogs, sheep, and rabbits over time periods ranging from 1 to $144 \mathrm{~h}(7,8,11,12)$. Fourth, other investigators have recently reported that albumin is the superior molecule for quantifying alterations in epithelial permeability in sheep (28). In that study, a smaller molecule (diethylenetriamine-pentaacetate, DTPA, mol wt 492) and a larger molecule (aggregated albumin, mol wt 383,000) were compared to human serum albumin (mol wt 69,000). The small molecule, DTPA, did not discriminate lung injury from lung inflation and the aggregated albumin did not discriminate the degree of lung injury (28).

Also we have reported that the ${ }^{125}$ iodine and the ${ }^{131}$ iodine labels remain tightly bound to albumin in both our prior studies $(8,12)$ and in these studies. Finally, we have recently reported on the clinical value of sequential albumin concentrations in the edema fluid of patients with acute lung injury as a prognostic indicator of recovery from alveolar edema and acute respiratory failure (29).

Although albumin is a good indicator of changes in epithelial protein permeability, there are other issues to be considered with a method designed to measure a change in epithelial permeability. First, are changes in the alveolar or vascular surface area likely to produce significant changes in clearance in either direction of the test molecule across the epithelium under the conditions of these studies? In our studies, alveolar surface area should be reasonably constant because the alveolar protein tracer is instilled into the same $20-30 \%$ of one lower lobe in all studies, as verified by prior studies of alveolar surface area (as quantified by Evans blue) and pulmonary blood flow, as measured by microspheres (7). The pattern of ventilation or the absolute transpulmonary pressure could theoretically influence alveolar protein clearance, but we have not found any difference in the rate of alveolar protein clearance in dogs or 

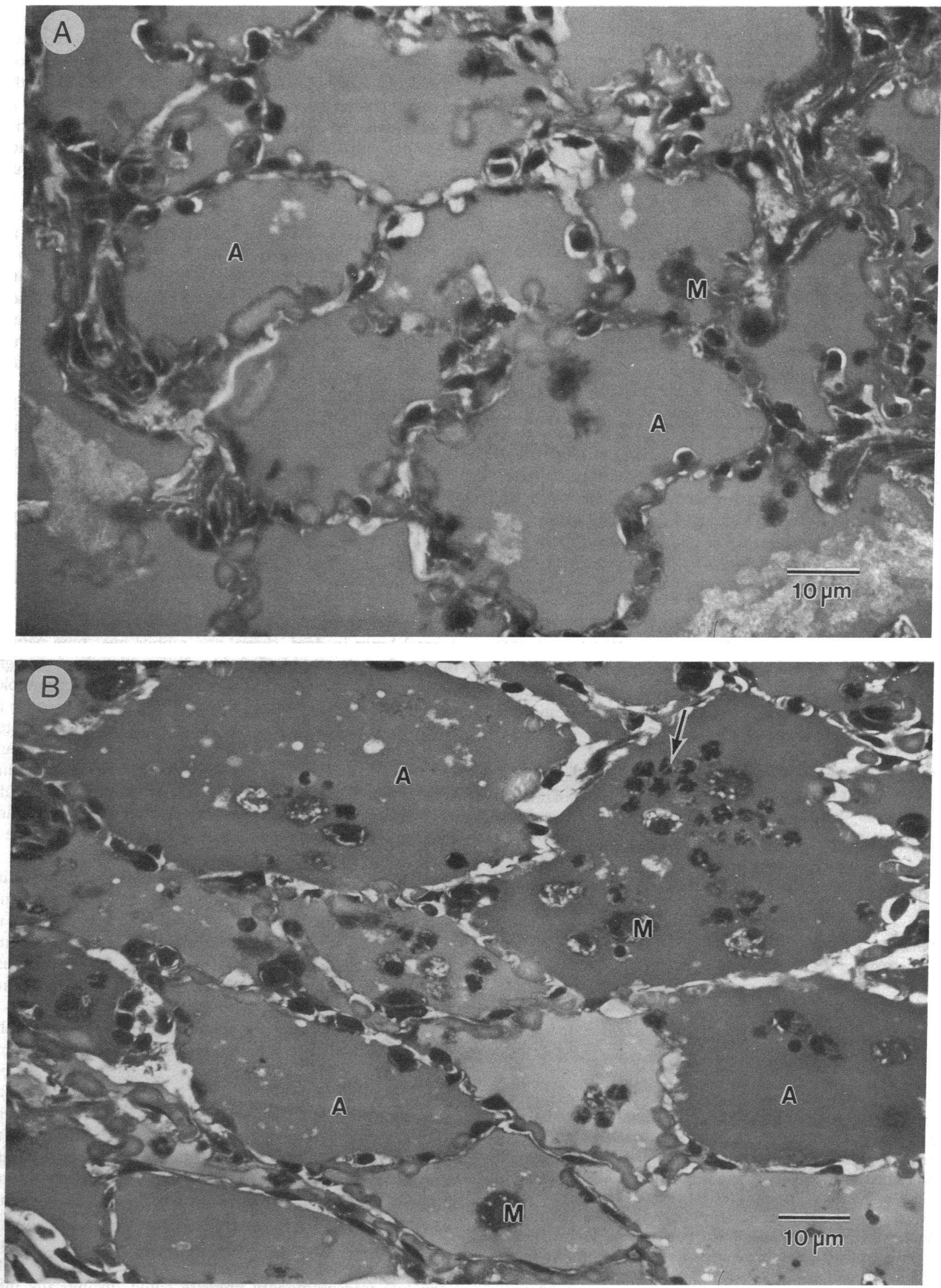

Figure 3. Histologic appearance of lung taken $4 \mathrm{~h}$ after instillation of serum in a group 2 sheep $(A)$ compared to sample taken $4 \mathrm{~h}$ after instillation of serum with $100 \mu \mathrm{g} / \mathrm{kg} E$. coli endotoxin in a group 4 sheep $(B)$. $(A)$ Air spaces $(A)$ are filled with instilled serum and contain alveolar macrophages $(M)$ and very few neutrophils. $(B)$ Alveolar air spaces $(A)$ are filled with alveolar macrophages $(M)$ and numerous neutrophils $($ arrow) which are not adjacent to the alveolar epithelium. 


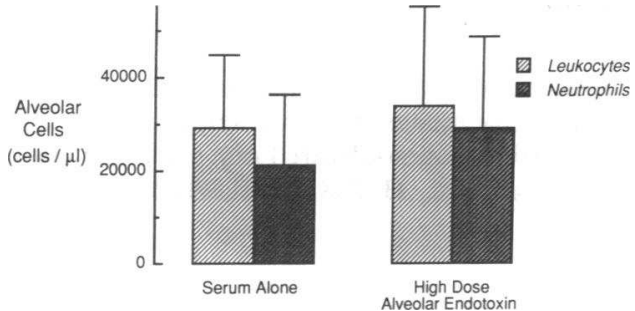

Figure 4. The number (mean \pm SD) of leukocytes and neutrophils entering the alveolar liquid after $24 \mathrm{~h}$ is shown for serum alone and group 4 sheep (high-dose alveolar E. coli endotoxin). With serum alone, the number of leukocytes and neutrophils present in the alveolar fluid is greater at $24 \mathrm{~h}$ compared to the 4-h studies (Fig. 2). However, by $24 \mathrm{~h}$, there is no difference between the number of leukocytes and neutrophils in the alveolar fluid in the serum alone compared with the high-dose alveolar $E$. coli endotoxin experiments.

sheep in whom the mode of ventilation was spontaneous or by positive pressure $(8,12,20)$. Also, Peterson et al. (28) did not find an effect of $10 \mathrm{~cm} \mathrm{H}_{2} \mathrm{O}$ positive end-expiratory pressure on albumin clearance from the air spaces in sheep. Could an alteration in pulmonary blood flow affect alveolar protein clearance? Interestingly, alveolar and lung protein clearance is not increased by augmenting pulmonary blood flow (7) or by eliminating pulmonary blood flow (30), probably because of the presence of lung lymphatics and bronchopulmonary anastomatic flow. Finally, the concentration of the alveolar protein tracer, ${ }^{125} \mathrm{I}$-albumin, remains high in the air spaces relative to the vascular compartment in the normal lung. The $T 1 / 2$ for clearance from the alveoli is $40 \mathrm{~h}$ (12). In the presence of modest epithelial injury delivered from the air spaces, as in the $24 \mathrm{~h}$ group six Pseudomonas studies, more of the alveolar tracer escapes into the vascular compartment and the residual quantity in the lung will be less, as occurred in the positive control studies with Pseudomonas (Table III). Other investigators have reported that an alveolar protein tracer will appear more rapidly in the vascular space after alloxan was instilled into the air spaces of dogs (15).

Is the use of a vascular protein tracer, ${ }^{131} \mathrm{I}$-albumin, useful and reliable as an index of epithelial permeability into the air spaces? A vascular protein tracer has been used, of course, in many prior studies as an index of altered endothelial permeability in the lung and other organs. However, surface area, hydrostatic pressure, and equilibration of the vascular protein tracer can confound interpretation of the data (27). In our studies, we have demonstrated, first of all, that accumulation of the vascular protein tracer in the lung was five- to sixfold greater with intravenous endotoxin than in control studies with serum alone or with modest left atrial hypertension, thus indicating that the data in this study with intravenous endotoxin did increase lung endothelial permeability in sheep. However, is it a sensitive and useful indicator of altered epithelial permeability? In the oleic acid 4-h experiments, there was a fourfold increase in the accumulation of the vascular tracer in the air spaces, which did not occur after left atrial hypertension matched to the elevation of lung microvascular pressure in the oleic acid studies. Secondly, in the setting of a milder epithelial injury with Pseudomonas, there was a twofold increase in equilibration of the vascular tracer (Table III), which matches well with the data on the modest increase in the clearance of the alveolar tracer ( ${ }^{125} \mathrm{I}$-albumin) and the modest reduction in lung liquid clearance (Table V). Other investigators (31) as well as work from our own laboratory (12) have shown that a vascular protein tracer equilibrates slowly across the normal alveolar epithelial barrier so this tracer should be useful in both short term studies ( $4 \mathrm{~h})$ as well as in somewhat longer studies ( $24 \mathrm{~h})$.

Also, it is apparent that the protein movement across the epithelial barrier may not be altered to the same degree in both directions. In the Pseudomonas studies, there was an equivalent change in bidirectional protein permeability with Pseudomonas, but after oleic acid injury in the 4-h experiments, the primary change in protein transfer was predominantly a unidirectional influx into the air spaces. Thus, by utilizing both a vascular and alveolar protein tracer, the magnitude of the bidirectional protein flux after lung injury can be compared.

Finally, although we have primarily relied on labeled albumin to quantify bidirectional changes in alveolar epithelial permeability, our results also provide data regarding net alveolar solute and liquid clearance. If there were a significant alteration in epithelial permeability to small molecules, then it is unlikely that alveolar solute and liquid clearance would be normal. In fact, alveolar liquid clearance was normal in the endotoxin experiments, as demonstrated by the increase in alveolar protein concentration to levels well above the plasma protein concentration in the endotoxin experiments (Tables IV and V).

Our data regarding the resistance of the alveolar epithelial barrier to endotoxin-induced injury may seen somewhat unexpected. Conceivably, alveolar epithelial cell transport mechanisms might be expected to be altered by endotoxin. Rats given intravenous $E$. coli endotoxin develop active ion transport abnormalities in liver slices (32) and dogs given $E$. coli endotoxin have an impaired $\mathrm{Na}^{+}-\mathrm{Ca}^{2+}$ exchange in cardiac sarcolemma (33). Also, in vitro work has suggested that alveolar epithelial cells exposed to phagocytosing neutrophils develop a change in permeability (34). Furthermore, monolayers of rat alveolar epithelial cells exposed to stimulated human neutrophils are killed by the neutrophils when the latter are tightly adherent to the monolayers (35). In our experiments, particularly in the alveolar $E$. coli endotoxin experiments, we found neutrophils adjacent to but not resting on the alveolar epithelium (Fig. $3 \mathrm{~B}$ ), suggesting that the consequences of epithelial cell neutrophil interaction in vitro may not apply to in vivo circumstances. Also, Meyrick has reported some morphologic changes of type I pneumocytes $60 \mathrm{~min}$ after $1.25 \mu \mathrm{g} / \mathrm{kg}$ of $E$. coli endotoxin was infused intravenously into anesthetized sheep. She found increased electron density of the epithelial cells and in a few regions there was disruption and loss of the type I pneumocytes leaving areas of bare basement membrane (5). Indeed, Meyrick's pathologic study in part stimulated us to physiologically test the hypothesis that $E$. coli endotoxin might injure the alveolar epithelial barrier. However, we found no morphologic or physiologic evidence of injury to the alveolar epithelial barrier or change in its ability to remove excess liquid from the air spaces of the lung in either 4- or 24-h studies. Conceivably, an injurious effect of $E$. coli endotoxin on lung epithelial barrier function might occur with a more prolonged exposure to intravenous $E$. coli endotoxin. However, one study of $24 \mathrm{~h}$ of continuous infusion of intravenous $E$. coli endotoxin $(24 \mathrm{ng} / \mathrm{kg}$ per $\mathrm{h}$ ) did not report the development of alveolar edema; in that study, the major deleterious effects of the continuous endotoxin infusion seemed to be on the pulmonary and systemic endothelium with increased lung lymph flow and reductions in 
systemic vascular resistance (36). Also, we did administer 500 $\mu \mathrm{g} / \mathrm{kg}$ intravenously to two sheep with no alteration in epithelial protein flux.

Some experimental data supports the concept that the alveolar cells may be more resistant to injury than lung endothelial cells. One study found the concentration of hydrogen peroxide required to kill alveolar epithelial cells was 14 times higher than the concentration required to kill bovine pulmonary artery endothelial cells (35). Furthermore, the alveolar epithelium appears to be more resistant to hyperoxic-induced injury than the lung endothelium (37). However, our study is the first one to compare the effects of $E$. coli endotoxin on the lung endothelium and alveolar epithelium in vivo simultaneously in one species and to demonstrate that the alveolar epithelium is resistant to the injurious effects of both intravenous or alveolar $E$. coli endotoxin.

There was an impressive chemotactic effect of $E$. coli endotoxin recruiting leukocytes and neutrophils into the air spaces in the 4-h high-dose alveolar E. coli endotoxin studies (Fig. 2). However, this effect was not associated with increased influx of the vascular protein tracer $\left({ }^{131} \mathrm{I}\right.$-albumin) nor an increase in the clearance of the alveolar protein tracer $\left({ }^{125} \mathrm{I}\right.$-albumin) (Table II). This is an interesting result because it demonstrates that the alveolar epithelium has the ability to permit the influx of large numbers of inflammatory cells without a concomitant change in epithelial permeability to protein. We reported a similar finding in sheep studies in which either sterile autologous serum, heparinized plasma, or 5\% ovine albumin in Ringer's lactate had been instilled into the air spaces (8). Also, a recent clinical study demonstrated that very large numbers of neutrophils can be attracted to the air spaces by instillation of $5 \times 10^{-7} \mathrm{M}$ leukotriene $B_{4}$ into normal human lungs without any increase influx of albumin or immunoglobulins into the air spaces (38). Therefore, our finding that alveolar $E$. coli endotoxin can cause large numbers of leukocytes to migrate across a tight epithelial barrier without changing alveolar epithelial permeability to protein is consistent with both prior experimental and clinical work.

Finally, a novel finding in this study is that when intravenous $E$. coli endotoxin was administered before instilling serum alone or serum plus $E$. coli endotoxin (group 2 and 3 sheep), the number of neutrophils that entered the air spaces was less than in control studies (Figs. 2 and 3). The explanation for this finding may relate in part to increased trapping or adherence of the activated neutrophils in the pulmonary capillaries after intravenous $E$. coli endotoxin. Recent studies have suggested that alterations in the physical characteristics of activated neutrophils may mediate neutrophil sequestration in the pulmonary capillaries $(39,40)$. Enhanced expression of adhesion molecules may also contribute to neutrophil sequestration, although the data supporting this mechanism in the lung endothelium are inconclusive (41). Our results imply that the location and sequence of appearance of chemoattractants may be important determinants of neutrophil migration.

In conclusion, $E$. coli endotoxin, administered intravenously or in high doses in the air spaces of the lung, does not increase alveolar epithelial permeability to protein or alter normal alveolar epithelial solute and liquid clearance. The resistance of the alveolar epithelial barrier to $E$. coli endotoxin injury is one important mechanism that prevents the development of alveolar edema in the presence of endotoxin-induced lung endothelial injury.

\section{Acknowledgments}

The authors thank Sanja Djukic, Robert Borntraeger, and Carol Baumeister for their help in preparation of this manuscript.

This work was supported by National Heart, Lung, and Blood Institute grants HL19155, HL40626, HL25816, HL38075, and S10 RR04910.

\section{References}

1. Rinaldo, J. E., J. E. Henson, J. H. Dauber, and P. M. Henson. 1985. Role of alveolar macrophages in endotoxin-induced neutrophilic alveolitis in rats. Tissue \& Cell. 17:461-472.

2. Haslett, C., G. S. Worthen, P. C. Giclas, D. C. Morrison, J. E. Henson, and P. M. Henson. 1987. The pulmonary vascular sequestration of neutrophils in endotoxemia is initiated by an effect of endotoxin on the neutrophil in the rabbit. Am. Rev. Respir. Dis. 136:9-18.

3. Hogg, J. C. 1987. Neutrophil kinetics and lung injury. Physiol. Rev. 67:1249-1295.

4. Heflin, A. C., and K. L. Brigham. 1981. Prevention by granulocyte depletion of increased vascular permeability of sheep lung following endotoxemia. $J$. Clin. Invest. 68:1253-1260.

5. Meyrick B., and K. L. Brigham. 1983. Acute effects of $E$. coli endotoxin on the pulmonary microcirculation of anesthetized sheep: structure-function relationships. Lab. Invest. 48:458-470.

6. Brigham K. L., and B. Meyrick. 1986. Endotoxin and lung injury. Am. Rev. Respir. Dis. 133:913-927.

7. Berthiaume, Y., N. C. Staub, and M. A. Matthay. 1987. Beta-adrenergic agonists increase lung liquid clearance in anesthetized sheep. J. Clin. Invest. 79:335-343.

8. Matthay, M. D., Y. Berthiaume, and N. C. Staub. 1985. Long-term clearance of liquid and protein from the lungs of unanesthetized sheep. J. Appl. Physiol. 59:928-935.

9. Salzer, W. L., and C. E. McCall. 1988. The biochemistry of endotoxin. Mol. Asp. Med. 10:517-548.

10. Meyrick, B. O., U. S. Ryan, and K. L. Brigham. 1986. Direct effects of $E$. coli endotoxin on structure and permeability of pulmonary endothelial monolayers and the endothelial layers of intimal explants. Am. J. Pathol. 122:140-151.

11. Berthiaume, Y., V. C. Broaddus, M. A. Gropper, T. Tanita, and M. A. Matthay. 1988. Alveolar liquid and protein clearance from normal dog lungs. $J$. Appl. Physiol. 65:585-593.

12. Berthiaume, Y., K. H. Albertine, M. Grady, G. Fick, and M. A. Matthay. 1989. Protein clearance from the air spaces and lungs of unanesthetized sheep over 144 h. J. Appl. Physiol. 67:1887-1897.

13. Wiener-Kronish, J. P., V. C. Broaddus, K. H. Albertine, M. A. Gropper, M. A. Matthay, and N. C. Staub. 1988. Relationship of pleural effusions to increased permeability pulmonary edema in anesthetized sheep. J. Clin. Invest. 82:1422-1429.

14. Landolt, C. C., M. A. Matthay, K. H. Albertine, P. J. Ross, J. P. WienerKronish, and N. C. Staub. 1983. Overperfusion, hypoxia, and increased pressure cause only hydrostatic pulmonary edema in anesthetized sheep. Circ. Res. 52:335-341.

15. Nelson, R. M. B. R. McIntyre, and E. A. Egan. 1978. Solute permeability of the alveolar epithelium in alloxan edema in dogs. J. Appl. Physiol. 44:353-357.

16. Selinger, S. L., R. D. Bland, R. H. Demling, and N. C. Staub. 1975. Distribution of volume of ${ }^{131} \mathrm{I}$-albumin, ${ }^{14} \mathrm{C}$-sucrose and ${ }^{36} \mathrm{Cl}$ in sheep lung. $J$. Appl. Physiol. 39:773-779.

17. Bongard, F. S., M. A. Matthay, R. C. Macrersie, and F. R. Lewis. 1984. Morphologic and physiologic correlates of increased extravascular lung water. Surgery (St. Louis). 96:395-401.

18. Albertine, K. H., J. P. Wiener-Kronish, K. Koike, and N. C. Staub. 1984 Quantification of damage by air emboli to lung microvessels in anesthetized sheep. J. Appl. Physiol. 57:1360-1368.

19. Zar, J. H. 1974. Biostatistical Analysis. Prentice-Hall, Inc., Englewood Cliffs, NJ.

20. Matthay, M. A., C. C. Landolt, and N. C. Staub. 1982. Differential clearance of liquid and protein from the alveoli of anesthetized sheep. J. Appl. Physiol. 53:96-104.

21. Montaner, J. S. B., J. Tsang, K. G. Evans, J. B. Mullen, A. R. Burns, D. C. Walker, B. Wiggs, and J. C. Hogg. 1986. Alveolar epithelial damage: a critical difference between high pressure and oleic acid induced low pressure pulmonary edema. J. Clin. Invest. 77:1786-1796.

22. Allen, S. J., R. E. Drake, J. Katz, J. C. Gabel, and G. A. Laine. 1987 Elevation of superior vena caval pressure increases extravascular lung water after endotoxemia. J. Appl. Physiol. 62:1006-1109.

23. Esbenshade, A. M., J. Newman, P. Lams, P. H. Jolles, and K. Brigham. 1982. Respiratory failure after endotoxin infusion in sheep: lung mechanics and lung fluid balance. J. Appl. Physiol. 53:967-976. 
24. Gabel, J. C., T. N. Hansen, and R. E. Drake. 1984. Effect of endotoxin on lung fluid balance in unanesthetized sheep. J. Appl. Physiol. 56:489-494.

25. Olson, N. C. 1988. Physiologic aspects of endotoxemia. Mol. Asp. Med. 10:551-629.

26. Welsh, C. H., I. M. Dauber, and J. V. Weil. 1986. Endotoxin increases pulmonary vascular protein permeability in the dog. J. Appl. Physiol. 61:13951402.

27. Staub, N. C. 1980. The pathogenesis of pulmonary edema. Prog. Cardiovasc. Dis. 23:53-80.

28. Peterson, B. T., K. D. Dickerson, H. L. James, E. J. Miller, J. W. McHarty, and D. B. Holiday. 1989. Comparison of three tracers for detecting lung epithelial injury in anesthetized sheep. J. Appl. Physiol. 66:2374-2383.

29. Matthay, M. A., and J. P. Wiener-Kronish. 1990. Intact epithelial barrier function is critical for the resolution of alveolar edema in humans. Am. Rev. Respir. Dis. 142:1250-1257.

30. Jayr, C., and M. A. Mathay. 1991. Alveolar and lung liquid clearance in the absence of pulmonary blood flow. J. Appl. Physiol. In press.

31. Gorin, A. B., and P. A. Stewart. 1979. Differential permeability of endothelial and epithelial barriers to albumin flux. J. Appl. Physiol. 47:1315-1324.

32. Sayeed, M. 1987. Ion transport in sepsis. Am. J. Physiol. 252:R809-821.

33. May-Shung, L., and Y. Xuan. 1989. Mechanisms of endotoxin-induced impairment in $\mathrm{Na}^{+}-\mathrm{Ca}^{2+}$ exchange in canine myocardium. Am. J. Physiol. 251:R1078-R1085.
34. Sugahara, K., G. R. Cott, P. E. Parsons, R. J. Mason, R. A. Sandhaus, and P. M. Henson. 1986. Epithelial permeability produced by phagocytosing neutrophils in vitro. Am. Rev. Respir. Dis. 133:875-881

35. Simon, R. H., P. D. De Hart, and R. F. Todd. 1986. Neutrophil-induced injury of rat pulmonary alveolar epithelial cells. J. Clin. Invest. 78:1375-1386.

36. Traber, D. L., J. T. Flynn, D. N. Herndon, H. Redl, G. Schlag, and L. D. Traber. 1989. Comparison of cardiopulmonary responses to single bolus and continuous infusion of endotoxin in an ovine model. Circ. Shock. 27:123-138.

37. De los Santos, R., J. J. Seidenfield, A. Anuzueto, J. F. Collins, J. J. Coalson, W. G. Johanson, and J. I. Peters. 1987. One hundred percent oxygen lung injury in adult baboons. Am. Rev. Respir. Dis. 126:657-661.

38. Martin, T. R., B. P. Pistorese, E. Y. Chi, R. B. Goodman, and M. A Matthay. 1989. Effect of leukotriene B-4 in the human lung. J. Clin. Invest. 84:1609-1619.

39. Erzurum, S. C., G. P. Downey, and G. S. Worthen. 1989. Bacterial lipopolysaccharide mediates microfilament-dependent retention of neutrophils in model capillaries. Am. Rev. Respir. Dis. 139:A298.

40. Worthen, G. S., B. Scwabb III, E. L. Elson, and G. P. Downey, 1989. Mechanics of stimulated neutrophils: cell stiffening induces retention in capillaries. Science (Wash. DC). 245:183-186.

41. Doerschuk, C. M., R. K. Winn, H. O. Coxson, and J. M. Harlan. 1990. CD18-dependent and independent mechanisms of neutrophil emigration in pulmonary and systemic microcirculation of rabbits. J. Immunol. 144:2327-2333. 